\title{
A questão da metalinguagem em uma disciplina de introdução aos estudos da tradução: uma proposta de unidade didática
}

\section{The question of metalanguage in an introductory course to Translation Studies: a Didactic Unit proposition}

Filipe Mendes Neckel*

Resumo: Este trabalho visa apresentar brevemente uma proposta de ensino de metalinguagem de tradução para um curso de Letras. 0 objetivo dessa proposta é ressaltar a relevância, para o aprendiz de tradução, da linguagem especializada referente à disciplina que está estudando. Utiliza-se como aporte teórico o conceito de tradução e de competência tradutória desenvolvidos por Amparo Hurtado Albir. Uma abordagem baseada em tarefas de tradução (HURTADO ALBIR 1999) é utilizada na construção da Unidade Didática apresentada. Também utiliza-se a abordagem por objetivos de aprendizagem, desenvolvida por Jean Delisle (1993) que prevê o ensino da metalinguagem como ponto de partida em um curso introdutório de tradução.

Palavras-chave: Didática de tradução; tarefas de tradução; objetivos de aprendizagem; metalinguagem; desenho de material didático.

Abstract: This paper aims to briefly present a proposition of translation metalanguage teaching for a Letters course. The goal of this proposition is to highlight the relevance, to the translation apprentice, of specialized language

\footnotetext{
Doutorando no Programa de Pós-graduação em Estudos da Tradução (PGET) na Universidade Federal de Santa Catarina. filipe_neckel@hotmail.com
} 
NECKEL, F. M. - A questão da metalinguagem em uma disciplina de introdução aos estudos da tradução: uma proposta de unidade didática

regarding the subject the apprentice is learning. A methodological approach of translation didactics based on solid pedagogical and theoretical principles allows a better construction of this knowledge. As theoretical support the concept of translation and translation competence developed by Amparo Hurtado Albir is used. In the elaboration of the Didactic Unit, an approach based on translation tasks is presented (HURTADO ALBIR 1999). We also make use of the learning goals approach, developed by Jean Delisle (1993), which forsees the teaching of metalanguage as a starting point in an introductory course in translation.

Keywords: Translation didactics; translation tasks; learning objectives; metalanguage; didactic materials design.

\section{Introdução}

Este trabalho tem por objetivo apresentar uma sugestão de unidade didática com foco no ensino da metalinguagem para alunos iniciantes em um curso de Letras, em uma disciplina de introdução aos estudos da tradução. Não pretende-se, entretanto, prescrever maneiras de ensinar a tradução, ou determinar maneiras corretas de elaborar o material didático para tal disciplina.

A proposta está fundamentada em três pontos, um marco teórico, com o conceito de tradução utilizado, além da noção de competência tradutória e sua aquisição; um marco pedagógico com os objetivos de aprendizagem, conceito apresentado primeiramente por Jean Delisle; e, por fim, o marco metodológico que traz a abordagem baseada em tarefas de tradução, sugerida de modo sistemático por Amparo Hurtado Albir em sua obra Enseñar a traducir (1999).

Após isso, há uma reflexão sobre a questão da metalinguagem nos estudos da tradução e sua relevância nas fases iniciais do ensino, principalmente em relação ao que diz Jean Delisle em sua obra, La traduction 
NECKEL, F. M. - A questão da metalinguagem em uma disciplina de introdução aos estudos da tradução: uma proposta de unidade didática

raisonnée (1993), a qual apresenta a questão da metalinguagem como o primeiro objetivo de aprendizagem que deve ser ensinado ao aprendiz. Por fim, uma breve discussão sobre a sugestão de unidade didática baseada em tarefas que tem por objetivo justamente o ensino da metalinguagem. Tal unidade didática (UD), desenvolvida a partir do modelo de Hurtado Albir (1999), será realizada pelos alunos como forma tanto de avaliar seus conhecimentos prévios sobre a metalinguagem de tradução, quanto para introduzir a eles alguns conceitos-chave da disciplina. Para isso, o texto já citado de Delisle (1993) será utilizado como parâmetro de criação das tarefas que constituem a referida UD; entretanto, os alunos não precisariam ler nenhum material antes da realização das tarefas, todo o conhecimento será adquirido ao longo da UD. A unidade didática sobre metalinguagem é apresentada ao final do artigo como forma de sugestão de atividade sobre o tema.

\section{Dos quadros teórico, pedagógico e metodológico}

\subsection{Do conceito de tradução}

Um dos três pontos que demarcam este estudo é o quadro teórico. Para tanto, neste primeiro momento, é apresentado o conceito de tradução, do qual esta proposta parte. O seguinte conceito de tradução foi retirado de Hurtado Albir (1999), da obra Enseñar a traducir, onde a autora diz, "[a] tradução é texto, ato comunicativo e processo mental”1 (pp. 40). Essa é uma

\footnotetext{
${ }^{1}$ La traducción es texto, acto de comunicación y proceso mental. [Todas as traduções, quando não possuem publicações em português, foram realizadas por mim].
} 
NECKEL, F. M. - A questão da metalinguagem em uma disciplina de introdução aos estudos da tradução: uma proposta de unidade didática

concepção tradutológica integradora e abrangente, permitindo trabalhar com o fazer tradutório em várias dimensões, desde uma perspectiva textual e voltada ao produto, até uma visão que observa a tomada de decisão do tradutor e volta seu olhar para o processo tradutório.

A tradução como texto é percebida justamente não como um conjunto de frases isoladas, mas sim como uma unidade completa de significado e essas unidades são construídas de formas diversas nas diferentes línguas. Diversos elementos, ou "mecanismos de funcionamento textual ${ }^{2}$ " (HURTADo ALBIR 2011: 41), que devem ser levados em consideração, atuam sobre os textos, isto é, elementos coesivos e de coerência, a questão dos gêneros e a tipologia textual, que variam em uso e estilo nas diferentes línguas e culturas.

A tradução como ato comunicativo corrobora o ponto anterior, pois o texto, essa unidade completa, possui uma finalidade comunicativa, e a tradução não deve ser considerada apenas como o transporte de um material linguístico de uma língua para outra, mas sim a imbricação dessa língua com a cultura que será apresentada em outra língua e cultura. Desta forma, cabe ao tradutor construir esse ato comunicativo, essa ponte, não somente entre línguas, mas entre as culturas, adotando, para isso, métodos diferentes para realizar sua tarefa que estão ligados às características de sua cultura, às necessidades do receptor do texto, aos processos tradutórios de seu contexto, além dos encargos de tradução.

Por fim, a tradução como atividade comunicativa está ligada aos processos mentais realizados pelo tradutor, tanto no que diz respeito à compreensão do texto, do ato comunicativo, quanto à interpretação realizada para a produção do texto traduzido. Isto requer, do tradutor, conhecimentos e habilidades específicos, a fim de uma uniformização terminológica.

Esses três pontos apresentados por Hurtado Albir para o conceito de tradução criam, conforme dito, um enfoque integrado da tradução, pois

\footnotetext{
${ }^{2}$ Mecanismos de funcionamiento textual.
} 
NECKEL, F. M. - A questão da metalinguagem em uma disciplina de introdução aos estudos da tradução: uma proposta de unidade didática

permite relacionar diversos níveis de análise, tais como, os mecanismos textuais, contextuais e culturais, assim como as questões de competência tradutória e de interpretação da finalidade comunicativa do texto fonte e de sua tradução.

\subsection{Da competência tradutória}

Dando prosseguimento à construção do quadro teórico, apresenta-se agora a noção de competência tradutória. Esta competência, especificamente, está relacionada com o conceito de tradução como atividade cognitiva, pois segundo Hurtado Albir (2011) é a "competência que capacita o tradutor para efetuar as operações cognitivas necessárias para desenvolver o processo tradutório"3 (pp. 375).

A competência tradutória se diferencia da competência bilíngue, ou seja, é uma competência específica, um conhecimento experto, que se define como "categórico ou abstrato, tendo uma base ampla de conhecimentos, sendo consciente e explicitável, organiza-se em estruturas complexas e se aplica à resolução de problemas" ${ }^{4}$ (HURTADo ALBIR 2011: 379). Assim, do tradutor competente requer-se uma série de habilidades, ou subcompetências, que são constitutivas da competência tradutória e vão além da competência bilíngue, sendo esta apenas uma das subcompetências necessárias ao tradutor. 0 conhecimento experto em relação à tradução é composto tanto do conhecimento declarativo (teórico), quanto do procedimental (prático):

3 La competencia que capacita al traductor para efectuar las operaciones cognitivas necesarias para desarrollar el proceso traductor.

4 Categórico o abstracto, tener una base amplia de conocimientos, ser consciente y explicitable, estar organizado en estructuras complejas y ser aplicable a la resolución de problemas. 
NECKEL, F. M. - A questão da metalinguagem em uma disciplina de introdução aos estudos da tradução: uma proposta de unidade didática

O conhecimento declarativo consiste em saber que, é fácil de verbalizar, se adquire por exposição, e seu processamento é essencialmente controlado. 0 conhecimento procedimental, por outro lado, consiste em saber como, é difícil de verbalizar, adquirese pela prática e se processa essencialmente de maneira automática $^{5}$ (HURTADO ALBIR 2011: 380).

A seguir, as subcompetências que são utilizadas como formadoras da competência tradutória neste trabalho foram definidas pelo grupo espanhol PACTE ${ }^{6}$ (Processo de aquisição da competência tradutória e avaliação), em suas pesquisas empírico-experimentais, conforme segue:

- Subcompetência bilíngue: conhecimentos pragmáticos, que habilitam o tradutor a utilizar a língua de acordo com o contexto, a compreender as funções linguísticas e atos de fala e recria-los conforme as necessidades da cultura de chegada;

- Subcompetência extralinguística: está relacionada com os conhecimentos declarativos e refere-se a questões culturais, enciclopédicas e temáticas que o tradutor precisa conhecer e reconhecer ao realizar a tradução;

- Subcompetência de conhecimentos sobre tradução: está ligada aos princípios da tradução (métodos, procedimentos, tipos de problemas), além dos aspectos profissionais da tradução. Também acredito que a esta subcompetência relacionam-se os conhecimentos metalinguísticos que o tradutor adquirirá em seu estudo acadêmico, os quais serão abordados a seguir no item 4;

\footnotetext{
${ }^{5}$ El conocimiento declarativo consiste en saber qué, es fácil de verbalizar, se adquiere por exposición, y su procesamiento es esencialmente controlado. El conocimiento procedimental, por su parte, consiste en saber como, es difícil de verbalizar, se adquiere por práctica y se procesa esencialmente de manera automática.

${ }^{6} \mathrm{O}$ Grupo PACTE vem desenvolvendo pesquisas na área de competência tradutória e sua aquisição desde 1997, e tem como principal pesquisadora Amparo Hurtado Albir, a teórica baseia seus escritos recentes nas descobertas do grupo sobre competência tradutória.
} 
NECKEL, F. M. - A questão da metalinguagem em uma disciplina de introdução aos estudos da tradução: uma proposta de unidade didática

- Subcompetência instrumental: a capacidade do tradutor em utilizar ferramentas de tradução, tecnologias e saber documentar-se;

- Subcompetência estratégica: segundo o grupo PACTE, esta subcompetência ocupa lugar central na competência tradutória, pois é ela que garantirá a "eficácia do processo tradutório"7 (HURTADo ALBIR 2011: 396), visto que se relaciona com as outras subcompetências, permitindo que o tradutor competente ative os conhecimentos e habilidades necessários para realizar o processo tradutório. Através da subcompetência estratégica 0 tradutor planeja sua tradução, escolhe o método mais eficiente para realizála por meio de seu projeto tradutório, utiliza as outras subcompetências e consegue superar possíveis faltas ou problemas em relação às outras subcompetências.

- Componentes psicofisiológicos: estão ligados às atitudes e comportamentos necessários ao tradutor para realizar sua tarefa, assim como a componentes cognitivos. (HURTADo AlBIR 2011: 395-396).

A partir do que foi dito acima, é possível determinar que a competência tradutória seja componencial e se forma dessas subcompetências, além de também ser possível verificar que há uma relação entre conhecimentos declarativos e procedimentais, sendo estes últimos mais acentuados, porém, não se exclui completamente o saber teórico da competência tradutória.

\subsection{Da aquisição da competência tradutória}

Para concluir o quadro teórico utilizado nesta abordagem, trato brevemente da aquisição da competência tradutória, ou seja, do processo

${ }^{7}$ La eficacia del proceso traductor. 
NECKEL, F. M. - A questão da metalinguagem em uma disciplina de introdução aos estudos da tradução: uma proposta de unidade didática

necessário para que o aprendiz se torne um tradutor competente. Assim como no caso da competência tradutória, será utilizado como parâmetro para esta análise o conceito apresentado Hurtado Albir (2011) e baseado nas pesquisas do grupo PACTE: “a aquisição da competência tradutória é um processo de reconstrução e desenvolvimento das subcompetências da competência tradutória [...] e dos componentes psicofisiológicos”8 (pp. 407). O modelo do PACTE é definido como dinâmico e cíclico, justamente por este caráter de reconstrução das subcompetências, partindo de um nível iniciante, ou novato, até o conhecimento experto, e buscando integrar o conhecimento declarativo com o procedimental.

0 processo de aquisição se estabelece em inter-relação entre as subcompetências. Algumas subcompetências são ativadas mais fundamentalmente, tais como os conhecimentos sobre tradução, instrumental e estratégica, aparentemente por tratarem-se de subcompetências específicas da competência tradutória, e não aquelas que também estão ligadas à competência comunicativa em língua estrangeira, ou seja, as subcompetências bilíngue e extralinguística. Parece haver uma hierarquia no processo de aquisição também, tendo relevância a subcompetência estratégica, justamente por auxiliar na organização das outras subcompetências.

Do mesmo modo, também se tornam relevantes o contexto de aquisição da competência tradutória, o tipo de ensino e a metodologia utilizada para essa aquisição. No presente trabalho, são feitas algumas sugestões para a construção de uma unidade didática a ser aplicada em um curso acadêmico de Letras, utilizando uma abordagem cognitivo-construtivista, ou seja, a aprendizagem ocorre em contexto e o estudante forma ou constrói uma boa parte daquilo que aprende e compreende em função de sua experiência. A

\footnotetext{
${ }^{8}$ La adquisición de la competencia traductora es un proceso de reconstrucción y desarrollo de las subcompetencias de la competencia traductora [...] y de los componentes psicofisiológicos.
} 
NECKEL, F. M. - A questão da metalinguagem em uma disciplina de introdução aos estudos da tradução: uma proposta de unidade didática

metodologia parte da abordagem baseada em tarefas de tradução sugerida por Hurtado Albir (1999) e a construção de objetivos de aprendizagem apresentado por Jean Delisle $(1980 ; 1993)$, como quadro pedagógico, apresentado a seguir.

\section{Dos objetivos de aprendizagem}

Dentro do quadro pedagógico, se encontra o desenho de objetivos de aprendizagem. Esta abordagem foi apresentada a primeira vez, com o intuito de ensinar a tradução, pelo teórico Jean Delisle, em 1980, em sua obra intitulada L'Analyse du discours comme méthode de traduction. Nessa obra, Delisle propõe uma reflexão sobre a forma de ensinar a tradução que possua um método pedagogicamente mais desenvolvido, apresentando, para tanto, os objetivos de aprendizagem nos quais seu curso de tradução geral seria organizado.

0 autor divide seu método em duas partes: inicialmente trata da parte teórica, voltada ao educador, pois diz que mesmo que o tradutor profissional possa passar sem o conhecimento teórico, ao se ensinar a tradução, o empirismo já não é suficiente, sendo necessária uma reflexão mais organizada do ensino que será aplicado, a fim de alcançar uma maior eficácia pedagógica (DeLISLE 1980: 47). Em seguida, na parte prática, apresenta os objetivos e exemplos de ensino. A organização do ensino pensada por Delisle através de objetivos de aprendizagem é um dos grandes méritos da obra do teórico, pois, segundo Hurtado Albir (2011), "o ponto de partida de qualquer didática é o 
NECKEL, F. M. - A questão da metalinguagem em uma disciplina de introdução aos estudos da tradução: uma proposta de unidade didática

desenho de objetivos, já que constituem o esqueleto em torno do qual se constitui o ensino"9 (pp. 166).

Os objetivos de aprendizagem são definidos por Delisle em sua obra posterior, La traduction raisonnée (1993), segundo o autor, um objetivo de aprendizagem é a "descrição da intenção visada por uma atividade pedagógica e determina as mudanças duradouras de comportamento que ocorrerá ao estudante"10 (pp. 38), ou seja, é aquilo que se pretende que o aluno saiba ou os conhecimentos e habilidades que pretendemos que o aluno adquira ao final do processo de ensino/aprendizagem.

Delisle também apresenta oito objetivos gerais e 56 específicos para seu curso, entendendo por objetivo geral, "breve enunciado da intenção, formulado em termos mais ou menos precisos, que indicam o resultado para o qual o processo de aprendizagem conduz dentro de um programa de estudos ou de um curso. [...] 0 objetivo geral é formulado do ponto de vista do professor" (DelISLE 1993: 38). Para os objetivos específicos, dá a seguinte definição:

Enunciados, formulados em termos de comportamentos observáveis que descrevem o mais precisamente possível os resultados a que se conduzirá uma ou mais atividade pedagógica dentro de um programa de estudo ou de um curso. [...] 0 objetivo específico é redigido do ponto de vista do aluno e descreve aquilo que este será capaz de fazer ao fim da aprendizagem ${ }^{11}$. (DELISLE 1993: 38)

\footnotetext{
${ }^{9}$ El punto de partida de cualquier didáctica es el diseño de objetivos, ya que constituyen el esqueleto en torno al cual se confecciona la enseñanza.

${ }^{10}$ Description de l'intention visée par une activité pédagogique et précisant les changements durables de comportement devant s'opérer chez l'étudiant.

${ }^{11}$ Énoncé, formule en termes plus ou moins précis, qui indique les résultats auxquels doit conduire une ou plusieurs activités pédagogiques à l'intérieur d'un programme d'études oud'un cours. [...] L'objectif spécifique est rédigé du point de vue de l'étudiant et décrit ce que celui-ci devra être capable de faire au terme d'un apprentissage.
} 
NECKEL, F. M. - A questão da metalinguagem em uma disciplina de introdução aos estudos da tradução: uma proposta de unidade didática

A relevância de se estabelecer objetivos claros para a aprendizagem é justamente buscar maior eficiência para os processos de aprendizagem e para as intenções pedagógicas que se pretende alcançar. Por isso, nessa proposta de unidade didática, é preciso deixar claro quais são os objetivos geral e específicos que se procura alcançar visando, assim, uma melhor compreensão por parte do aluno do resultado a que este irá chegar ao final de seu processo de ensino/aprendizagem. Além disso, ter como fundamentação pedagógica de um processo didático o desenho de objetivos permite elaborar um currículo mais aberto e com mais possibilidades, amplia a comunicação entre o professor e o aluno, uma vez que esse ocupa papel central no processo, promove uma abrangência maior na escolha de métodos pedagógicos $\mathrm{e}$ diversifica a elaboração e uso do material didático e também cria uma base para a avaliação da aprendizagem, uma vez que os objetivos específicos podem ser revisitados e alterados ao longo do processo (HURTADO ALBIR 1999: 45).

A seguir é apresentado o último ponto que constitui esta tríade teóricopedagógico-metodológica, com o quadro metodológico desse trabalho, a saber, a abordagem por tarefas de tradução.

\section{Da abordagem por tarefas}

Utilizada desde os anos 80 no ensino de língua estrangeira, a abordagem por tarefas foi adaptada ao ensino de tradução. 0 método baseado em tarefas de tradução foi apresentado por Hurtado Albir (1999), e tem por definição de tarefa de tradução: uma unidade de trabalho em sala de aula, representativa da prática tradutória, que se dirige intencionalmente à aprendizagem da tradução e que está desenhada com um objetivo concreto, uma estrutura e uma sequência de trabalho (pp. 56). As atividades realizadas 
NECKEL, F. M. - A questão da metalinguagem em uma disciplina de introdução aos estudos da tradução: uma proposta de unidade didática

durante a tarefa conduzem o aluno ao mesmo fim, ou seja, a realização do objetivo da unidade didática, e nesse percurso "tanto conhecimento procedimental (saber como), quanto declarativo (saber o quê) são praticados e explorados"12 (DAVIES 2004: 232).

Assim, a tarefa é o núcleo organizador do processo de aprendizagem e a abordagem por tarefas de tradução propõe uma metodologia flexível na elaboração das unidades didáticas. As UDs constituem a progressão do curso e a realização dos objetivos de aprendizagem. Os pontos vantajosos na utilização de tarefas de tradução no ensino são, segundo Hurtado Albir (1999: 56): proporcionar uma metodologia ativa, aproximando esta dos objetivos do curso; propor um método centrado no processo, onde o estudante constrói seu conhecimento por meio de tarefas que o auxiliem na resolução de problemas; permitir a aquisição de estratégias para a realização da tradução e estratégias de aprendizagem; a pedagogia é centrada no aluno, tornando-o responsável por seu desempenho e dando a este autonomia na aquisição do conhecimento; criar a possibilidade de avaliação constante, de forma que o processo de ensino/aprendizagem possa ser alterado ao sentir necessidade.

Partindo dos pontos apresentados pela autora para definir o método, é possível verificar que há grande flexibilidade metodológica, pois o desenho curricular pode ser readaptado às dificuldades do aluno a qualquer momento, além disso, por ser pensada dentro de cada contexto educativo, desta forma, a proposta não é elaborar um modelo prescritivista, mas sim adaptável a cada situação e a cada contexto.

A tarefa, como núcleo organizador, forma as unidades didáticas (UDs), que são elaboradas em torno de um objetivo específico de aprendizagem, o qual deve ser apresentado ao início do processo. 0 modelo de UD criado por

\footnotetext{
${ }^{12}$ Both procedural (know how) and declarative (know what) knowledge are practised and explored.
} 
NECKEL, F. M. - A questão da metalinguagem em uma disciplina de introdução aos estudos da tradução: uma proposta de unidade didática

Hurtado Albir (1999: 56) será utilizado na elaboração dessa proposta, e é apresentado abaixo:

UNIDADE DIDÁTICA:
OBJETIVO:
ESTRUTURA DA UNIDADE
TAREFA 1:
TAREFA 2:
TAREFA 3:
TAREFA ...:
TAREFA FINAL

O número de tarefas em cada UD pode variar dependendo da necessidade, também sendo possível ocorrer tarefas de revisão, que retomem tarefas já produzidas em UDs anteriores. Cada tarefa é dividida em Fichas, isto é, as atividades que os alunos devem desempenhar.

A seguir, é apresentado o objetivo específico dessa proposta para a elaboração da unidade didática e das tarefas que a constituem.

\section{Da questão da metalinguagem}

Justamente por se tratar de uma metodologia que deve ser pensada dentro de cada contexto, o ponto de partida da sugestão desse material didático está localizado dentro do ensino acadêmico da tradução. Ou seja, seu desenvolvimento e aplicação foram pensados para terem lugar em um curso de Letras, mais especificamente em uma disciplina de Introdução aos Estudos da Tradução, ou que esteja relacionada com o ensino da tradução e que procure apresentar uma perspectiva integradora entre o conhecimento procedimental e o declarativo. 0 objetivo de aprendizagem prevê o aluno iniciante que tenha pouco ou nenhum contato com conhecimentos de tradução, estando nas fases iniciais do curso. 
NECKEL, F. M. - A questão da metalinguagem em uma disciplina de introdução aos estudos da tradução: uma proposta de unidade didática

O conhecimento declarativo abordado aqui não se limita exclusivamente à teoria da tradução, mas está ligado à reflexão tanto sobre o processo tradutório realizado pelo aprendiz-tradutor, quanto sobre o produto, o resultado desse processo, a tradução em si. Segundo Antoine Berman, "a tradução pode perfeitamente passar sem teoria, não sem o pensamento" (2007: 19), ou seja, sem uma reflexão por parte do tradutor e, justamente por tratar-se de um curso acadêmico, essa reflexão se faz mais presente na vida profissional do futuro tradutor.

Assim, uma UD que trate especificamente da questão metalinguística dos estudos da tradução parece se fazer necessária na formação do tradutor, principalmente, como sugere Delisle, se formos tratar de uma "aprendizagem fundamentada e metódica da tradução geral”13 (1993: 52). Assim, ao pensar em um curso de tradução geral, com uma metodologia ativa, promovendo a reflexão aprofundada sobre os processos tradutórios, parece haver também a necessidade de um objetivo de aprendizagem ligado aos conhecimentos metalinguísticos da tradução. Ainda conforme Delisle, a metalinguagem, as terminologias específicas, fazem parte de qualquer área de conhecimento e com a tradução não é diferente (1993: 52). Apropriar-se dessa metalinguagem dá ao aprendiz maior conhecimento sobre a área de estudo e o torna mais consciente dos processos realizados no ato tradutório, além disso, dota o mesmo de ferramentas que o permitem justificar suas escolhas tradutórias perante seus pares, integrando-o à comunidade que almeja fazer parte, ou seja, a de tradutores profissionais. Doutra parte, o conhecimento metalinguístico também faz com que o aprendiz não se sinta constrangido diante de críticas ao seu trabalho, sendo capaz de defendê-lo de forma pertinente e fundamentada.

A seguir, é apresentado o exemplo da UD desenvolvida para esta proposta, tendo como objetivo principal a assimilação das principais noções

\footnotetext{
${ }^{13}$ Un apprentissage raisonné et méthodique de la traduction générale.
} 
NECKEL, F. M. - A questão da metalinguagem em uma disciplina de introdução aos estudos da tradução: uma proposta de unidade didática

metalinguísticas dos estudos da tradução. Tomando por base a noção de competência, esse objetivo de aprendizagem está relacionado à subcompetência de conhecimentos sobre tradução, pois ativa conhecimentos declarativos não apenas sobre princípios que regem a tradução, mas também, em certa medida, sobre aspectos profissionais da tradução, uma vez que o conhecimento terminológico é compartilhado pela comunidade profissional de praticamente todas as áreas do conhecimento, e no campo da tradução isso não deveria ser diferente. Além disso, esse objetivo também parece ativar a subcompetência estratégica, pois dá ao tradutor não apenas o conhecimento teórico, de nomenclaturas, mas, por meio da metodologia empregada, o prepara para identificar e lidar com problemas de forma mais consciente, ao menos nas fases iniciais de sua formação.

\section{Do exemplo de unidade didática}

A unidade didática construída é constituída de três tarefas que preparam para uma tarefa final. A seguir, são descritas brevemente cada uma das tarefas da unidade. A UD é apresentada no apêndice deste trabalho.

A primeira tarefa foi pensada com o objetivo de diagnosticar o conhecimento dos alunos, pois pede que os aprendizes relacionem conceitos de tradução e suas definições, a partir de seus conhecimentos prévios. A Ficha 1 não possui material de apoio justamente por se tratar de um momento instintivo, por dizer assim, da parte do aluno, o objetivo é justamente pôr os alunos em contato com os termos a primeira vez.

Os termos que compõe a Ficha foram retirados da obra de Jean Delisle (1993). O glossário que o autor apresenta é constituído por aproximadamente 180 termos, assim, por se tratar de uma disciplina inicial e para não sobrecarregar os alunos, foi realizada uma seleção de 10 termos, provenientes 
NECKEL, F. M. - A questão da metalinguagem em uma disciplina de introdução aos estudos da tradução: uma proposta de unidade didática

de uma subdivisão feita pelo próprio Delisle, chamada Manipulação da Linguagem. Os termos se relacionam com o que o autor chama de procedimentos de transferência. A Ficha 2 da primeira tarefa pede que os alunos apresentem ao grande grupo suas escolhas e comparem suas respostas com as dos colegas, em seguida, recebem, como material de apoio as definições do glossário de Delisle para que corrijam a atividade.

A segunda tarefa traz, como leitura obrigatória, um breve trecho da obra de Heloísa Barbosa, Procedimentos técnicos da tradução: uma nova proposta. A Ficha 1 ainda apresenta um material de apoio que comenta brevemente a importância dessa metalinguagem para as áreas do conhecimento e para os estudos da tradução. Os alunos devem, então, a partir da leitura dos textos, relacionar os exemplos práticos apresentados com a metalinguagem correspondente. Nesse momento, em pequenos grupos, os alunos devem observar os exemplos apresentados e, a partir disso, completar com a nomenclatura para o processo utilizado, justificando sua resposta. A Ficha 2 pede contribuições com novos exemplos retirados da internet ou de qualquer material que os alunos possam sugerir. Finalmente, na Ficha 3 , as respostas e exemplos dos grupos são, então, compartilhadas com os colegas para discussão e aprofundamento para melhor compreensão das noções estudadas.

Para a terceira tarefa, o aluno responderá a algumas questões relativas aos termos e conceitos apresentados na primeira tarefa. Este processo pode auxiliá-lo a compreender melhor os termos. Esta tarefa também será realizada em pequenos grupos, pois parece importante que o conhecimento seja compartilhado e que os alunos saibam trabalhar em equipe.

A tarefa final se constitui de uma reportagem da edição online do jornal The New York Times, em língua estrangeira. Uma vez que o objetivo da UD não é ensinar o aluno a traduzir, mas sim que conheça e reconheça a metalinguagem dos estudos da tradução, a Ficha 1 pede que, após a leitura do texto, os alunos traduzam trechos específicos da reportagem e, a partir disso, 
NECKEL, F. M. - A questão da metalinguagem em uma disciplina de introdução aos estudos da tradução: uma proposta de unidade didática

comentem seu processo tradutório fazendo uso da metalinguagem de forma consistente e justificando suas escolhas de maneira coerente. 0 objetivo dessa tarefa é observar se o aluno apropriou-se, de fato, da metalinguagem concernente aos estudos da tradução. 0 exemplo apresentado nesse artigo é de um texto em inglês, mas, pode ser adaptado para outras línguas, cabendo ao professor selecionar os textos indicados para os alunos em sua disciplina.

\section{Considerações Finais}

O objetivo deste artigo foi tocar brevemente na questão da metalinguagem como forma de introduzir o aprendiz ao mundo dos estudos da tradução e, para tanto, foi proposta uma unidade didática fundamentada pedagogicamente e utilizando uma metodologia ativa. A ideia é que esse material possa contribuir para o desenvolvimento do ramo aplicado dos estudos da tradução, mais especificamente da didática da tradução.

Além disso, levando em conta as noções de competência tradutória e sua aquisição, acredito que a reflexão sobre os processos de ensino/aprendizagem de tradução, assim como a construção de material didático baseados em uma pedagogia bem fundamentada podem contribuir para o melhor entendimento daquelas noções e de como se dá o processo de aquisição da competência tradutória.

\section{Referencias bibliográficas:}

Barbosa, H. G. Procedimentos técnicos da tradução: uma nova proposta. Campinas, SP: Pontes, 2004. 
NECKEL, F. M. - A questão da metalinguagem em uma disciplina de introdução aos estudos da tradução: uma proposta de unidade didática

Berman, A. A Tradução e a Letra - Ou o albergue do longínquo. Trad.: MarieHélène Catherine Torres, Mauri Furlan, Andréia Guerine. Rio de Janeiro: 7Letras/PGET, 2007.

DAVIES, M. G. Multiple voices in the translation classroom - activities, tasks and projects. Amsterdam: John Benjamins Publishing, 2004.

DELISLE, J. L'Analyse du discours comme méthode de traduction. Editions de l'Université d'Ottawa, 1980.

d'Ottawa, 1993.

- La traduction raisonnée. Les Presses de l'Université

HURTADO AlBIR, A. Enseñar a traducir. Metodología en la formación de traductores e intérpretes: [Teoría y fichas prácticas]. Madrid: Edelsa, 1999.

A aquisição da competência tradutória: aspectos teóricos e didáticos. In: Competência em tradução - cognição e discurso. Adriana Pagano, Célia Magalhães, Fábio Alves. Belo Horizonte: Editora UFMG, 2005.

Traducción y traductología - introducción a la traductología.

Ediciones Cátedra, 2011.

Recebido em: 10 jun. 2015

Aprovado em: 15 dez. 2015 
NECKEL, F. M. - A questão da metalinguagem em uma disciplina de introdução aos estudos da tradução: uma proposta de unidade didática

\section{ANEXO 1}

PROPOSTA DE UNIDADE DIDÁTICA:

UNIDADE DIDÁTICA:

Conhecendo e reconhecendo a metalinguagem dos estudos da tradução.

OBJETIVOS: $\quad$ Sensibilizar o tradutor iniciante para a relevância do conhecimento metalinguístico dos estudos da tradução;

Mostrar ao estudante que a apropriação desse conhecimento pode ser significativa em sua atuação profissional, tanto no que concerne às suas escolhas tradutórias, quanto na justificativa das mesmas.

Incentivar o tradutor em formação para a reflexão sobre os processos que realiza no ato tradutório e a relevância de saber defender e justificar suas escolhas.

\section{ESTRUTURA DA UNIDADE}

Tarefa 1: $\quad$ Familiarizando-se com termos específicos dos estudos da tradução

Tarefa 2: $\quad$ Reconhecendo as noções metalinguísticas: exemplos práticos de usos dos termos

Tarefa 3: $\quad$ Apropriando-se da nomenclatura: questões sobre a metalinguagem dos estudos da tradução

Tarefa Final: Justificando escolhas: fazer uso das terminologias apresentadas para justificar as escolhas tradutórias realizadas.

TradTerm, São Paulo, v. 26, Dezembro/2015, pp. 57-86

www.usp.br/tradterm

http://www.revistas.usp.br/tradterm/index 
NECKEL, F. M. - A questão da metalinguagem em uma disciplina de introdução aos estudos da tradução: uma proposta de unidade didática

Tarefa 1 Familiarizando-se com termos específicos dos estudos da tradução

Na FICHA 1 encontram-se alguns termos específicos dos estudos da tradução e suas definições. Você deve relacionar o termo com a definição correta:

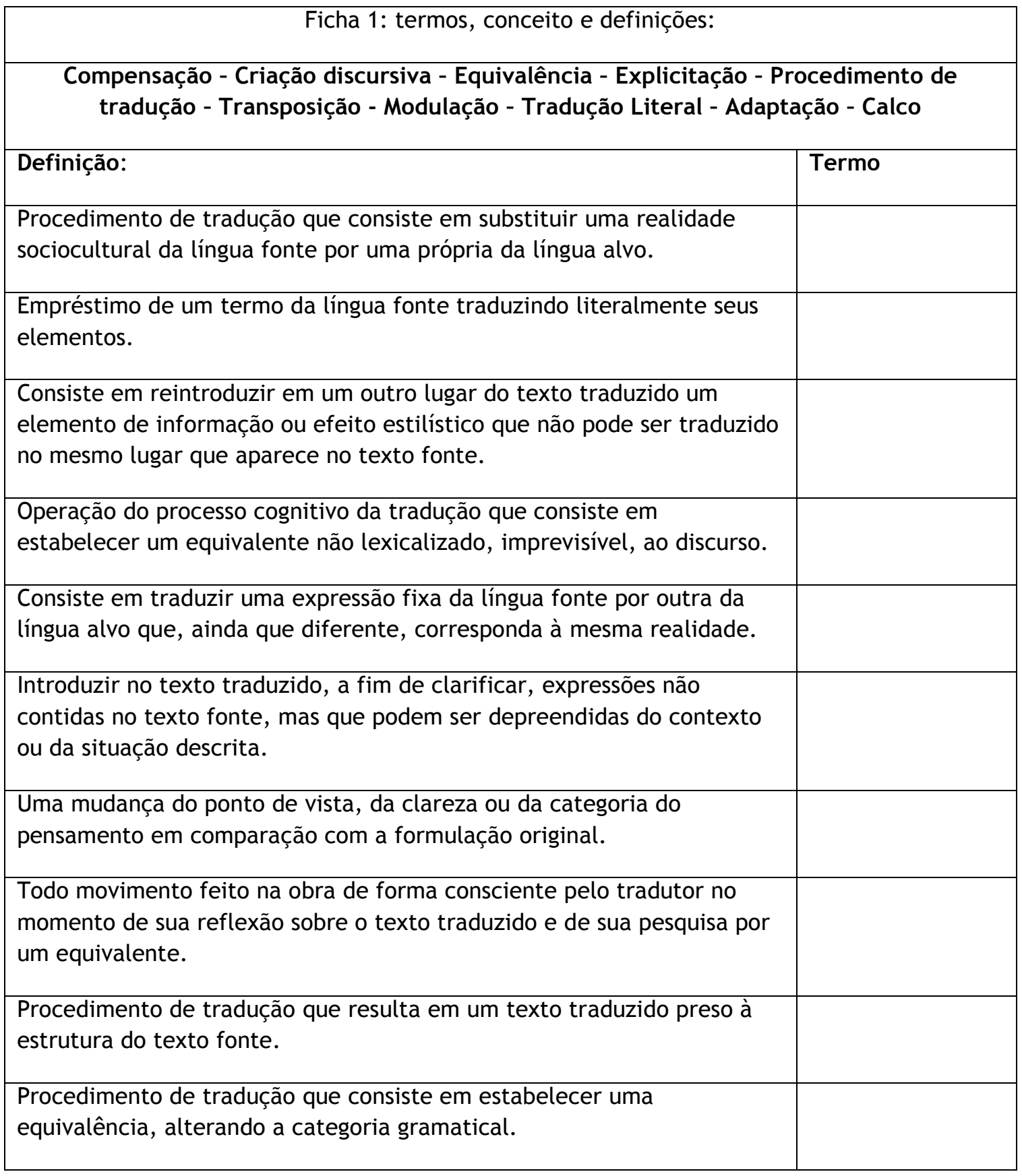

TradTerm, São Paulo, v. 26, Dezembro/2015, pp. 57-86

www.usp.br/tradterm

http://www.revistas.usp.br/tradterm/index 
NECKEL, F. M. - A questão da metalinguagem em uma disciplina de introdução aos estudos da tradução: uma proposta de unidade didática

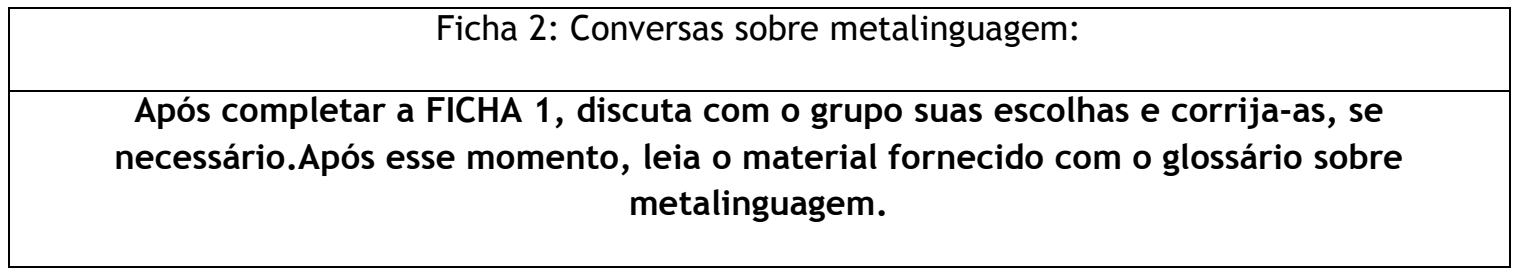

Tarefa 2 Reconhecendo as noções metalinguísticas: exemplos práticos de usos dos termos

\section{Material de apoio 1 - Reconhecendo a metalinguagem: exemplos práticos de usos dos termos}

Segundo Jean Delisle, em sua obra La traduction raisonnée (1993), todas as áreas do conhecimento possuem uma terminologia própria, esse é o caso também dos estudos da tradução. E torna-se fundamental para o aprendiz de tradução apropriar-se desse conhecimento em suas fases inicias de estudo. Os termos apresentados acima são uma pequena parcela da metalinguagem que constitui os estudos da tradução. Essas noções podem auxiliar a sua formação no sentido de indicar estratégias tradutórias ou reflexões sobre os processos tradutórios que o tradutor pode utilizar ao realizar sua atividade.

Delisle divide estes termos em quadros para auxiliar na assimilação destes conceitos:

- Resultado da operação de tradução: adaptação; tradução literal; tradução livre.

- Manipulação da linguagem: explicação; modulação; calco; transliteração.

- Linguística: estrangeirismo; aclimatação

- Reflexões teóricas: tradução como processo; tradução como produto; projeto tradutório.

Em grupos de dois ou três alunos, identifique os procedimentos utilizados nos exemplos abaixo e justifique suas respostas:

\begin{tabular}{|c|c|}
\hline \multicolumn{2}{|c|}{ Ficha 1: Alguns exemplos de usos dos termos: } \\
\hline Exemplo: & Termo e justificativa \\
\hline It is a known fact - Este é um fato conhecido & \\
\hline $\begin{array}{c}\text { Three ways to make life easier - três } \\
\text { maneiras de facilitar a vida }\end{array}$ & \\
\hline \begin{tabular}{c} 
Like the back of my hand - como a palma da \\
\hline
\end{tabular} & \\
\hline
\end{tabular}

TradTerm, São Paulo, v. 26, Dezembro/2015, pp. 57-86

www.usp.br/tradterm

http://www.revistas.usp.br/tradterm/index 
NECKEL, F. M. - A questão da metalinguagem em uma disciplina de introdução aos estudos da tradução: uma proposta de unidade didática

\begin{tabular}{|c|c|}
\hline minha mão & \\
\hline Knockout - nocaute & \\
\hline Гласность - Glasnost & \\
\hline Croissant - croissant & \\
\hline Textbook - livro texto & \\
\hline $\begin{array}{c}\text { Wall Street - o mercado financeiro de Nova } \\
\text { lorque }\end{array}$ & \\
\hline
\end{tabular}

Ainda em grupo, procure outros exemplos para os termos apresentados, preenchendo a FICHA 2:

\begin{tabular}{|l|l|}
\hline \multicolumn{2}{|c|}{ Ficha 2: aprimorando seus conhecimentos: } \\
\hline Termos & Exemplos: \\
\hline & \\
\hline & \\
\hline & \\
\hline & \\
\hline & \\
\hline
\end{tabular}

Agora apresente seus novos exemplos aos colegas e complete a FICHA 3 abaixo com os exemplos dos colegas:

\begin{tabular}{|l|l|}
\hline \multicolumn{2}{|c|}{ FICHA 3: Mais discussões } \\
\hline Termos & Exemplos: \\
\hline & \\
\hline & \\
\hline & \\
\hline & \\
\hline & \\
\hline
\end{tabular}

TradTerm, São Paulo, v. 26, Dezembro/2015, pp. 57-86

www.usp.br/tradterm

http://www.revistas.usp.br/tradterm/index 
NECKEL, F. M. - A questão da metalinguagem em uma disciplina de introdução aos estudos da tradução: uma proposta de unidade didática

\section{Tarefa 3 Apropriando-se da nomenclatura: questões sobre a metalinguagem dos}

\section{estudos da tradução}

Responda as questões a seguir dando o maior número de detalhes possível sobre os termos estudados a fim de melhor compreender suas noções:

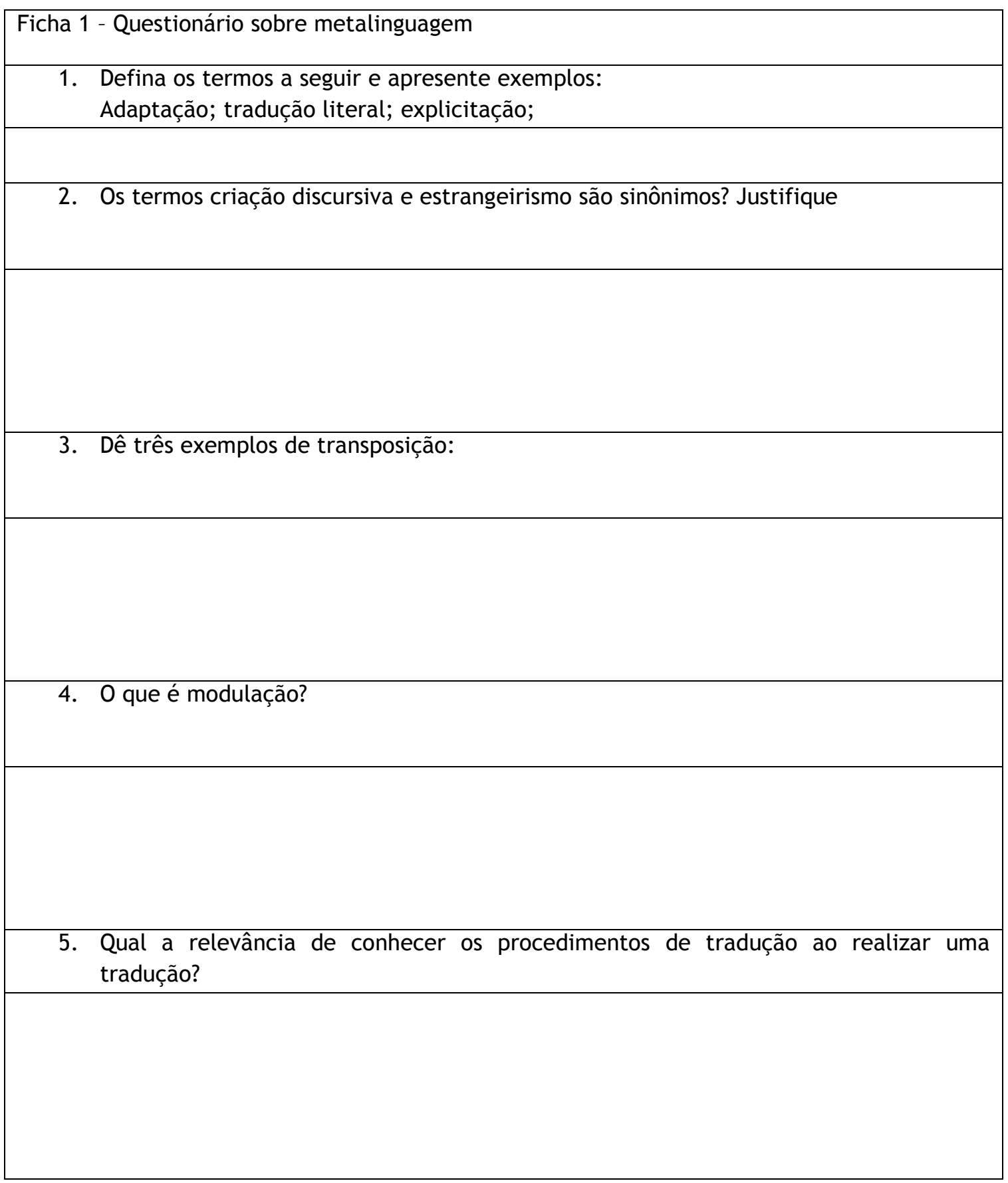

TradTerm, São Paulo, v. 26, Dezembro/2015, pp. 57-86

www.usp.br/tradterm

http://www.revistas.usp.br/tradterm/index 
NECKEL, F. M. - A questão da metalinguagem em uma disciplina de introdução aos estudos da tradução: uma proposta de unidade didática

Tarefa Final: Justificando escolhas: fazer uso das terminologias apresentadas para justificar as escolhas tradutórias realizadas.

Com base no que foi visto nessa UD, após ler a reportagem, traduza os seguimentos selecionados e indique os procedimentos utilizados no processo tradutório, justificando sua resposta:

\section{Decline of a Political Family Opens the Way for a Shift in Brazil}

The tribute is lavish. Slip into the Convento das Mercês, an elegantly restored colonial gem built here in 1654, and learn of the feats of José Sarney, a former president of Brazil and chief of the political dynasty that has held sway over the vast northeast state of Maranhão for five decades.

A documentary depicts Mr. Sarney as a generously mustachioed governor lifting Maranhão (pronounced mar-ah-NEEOW) from its economic isolation in the 1960s. Photos capture him presiding over Brazil's transition to civilian rule in the 1980s. A display of titles, including "Master of the Sea," show his literary prowess as a novelist-statesman.

Outside the Convento das Mercês, which houses a state-financed foundation heralding Mr. Sarney, residents are quick to point out the family's mark all around São Luís, the state capital.

Need a place to live? Consider the neighborhood of Vila Sarney, they joke. A hospital? There is the Maternidade Marly Sarney. Want to check out a book? Try the José Sarney Library. Need to go to the old center? Take the José Sarney Bridge.

And if you have a problem, you can always file a lawsuit - at the Sarney Costa Courthouse.

But all the visible celebration of Mr. Sarney now stands in sharp contrast to the way the patriarch, 84, and his offspring are widely perceived both in Maranhão, one of Brazil's poorest states, and the rest of Brazil.

Voters ousted Mr. Sarney's political loyalists in Maranhão in state elections in October, and Mr. Sarney, long one of Brazil's most powerful men from his perch in the Senate, announced that he would not seek re-election, possibly opening the way for one of the more profound shifts in Brazilian politics in recent years.

"The last great colonels of Brazil are finally in decline," said Rodrigo Lago, a lawyer and transparency activist, using the term for the strongmen asserting power over big areas of Brazil, largely here in the nation's poor northeast.

"If Maranhão can change, then oligarchies elsewhere can be curbed in this country," he added.

TradTerm, São Paulo, v. 26, Dezembro/2015, pp. 57-86

www.usp.br/tradterm

http://www.revistas.usp.br/tradterm/index 
NECKEL, F. M. - A questão da metalinguagem em uma disciplina de introdução aos estudos da tradução: uma proposta de unidade didática

Powerful dynasties elsewhere in Brazil are showing signs of strain. In Paraíba, another northeast state, the son of Ronaldo Cunha Lima, a former governor who infamously shot his predecessor in a crowded restaurant in 1993 without ever serving time for attempted murder, lost a bid for governor this year.

Similarly, voters recently thwarted the son of Jader Barbalho - a powerful senator with a regional media empire who has long battled corruption charges - from being elected governor of Pará, the huge state in the Amazon bordering Maranhão.

Of course, powerful political families are resilient, and dynasties can always mount a comeback. In Alagoas, one of Brazil's poorest states, the 34-year-old son of Renan Calheiros, the president of Brazil's Senate, was elected governor in October.

While President Dilma Rousseff is from the leftist Workers Party, she has little choice but to forge alliances with centrist or conservative parties, some led by old-school political chiefs.

But here in the Sarney bastion of Maranhão, many people are sanguine about the chances of finally turning a corner.

"We're done with the Sarneys, who stayed in power just to enrich themselves," said Sueli Celeste, 48, the secretary at a school near the Convento das Mercês in the old center of São Luís, which abounds in one derelict palazzo after another.

"Hide your phone when you walk around here," she added. "The crack addicts will steal it if they see you taking pictures."

The roots of resentment are not hard to see. Maranhão remains one of Brazil's poorest states, with many of its people eking out an existence as subsistence farmers.

Yet the Sarney family has managed to assemble a powerful collection of mass media holdings, including the newspaper 0 Estado de Maranhão and TV Mirante, an affiliate of the Globo television network, enabling the clan to celebrate its achievements and attack its critics.

"The media constantly extol the great things Sarney and his allies have done and are doing," said Sean Mitchell, an anthropologist at Rutgers University who has conducted extensive research in Maranhão. "Despite this, the provision of public services by the Sarney family and allied officeholders is terrible."

Maranhão ranks second to last among Brazil's 26 states in the United Nations Human Development Index, a comprehensive measure of factors like education levels, incomes and life expectancy.

Writing this year in his Sunday column in O Estado de Maranhão, the Sarney family's newspaper, Mr. Sarney argued that the development index was created as a strategy by "imperialist countries" to exploit weaknesses in the developing world.

"This is the index they crow about when they want to talk bad about Brazil and worse about Maranhão," he said. (The index was actually created by a Nobel laureate from India and a former finance minister of Pakistan).

TradTerm, São Paulo, v. 26, Dezembro/2015, pp. 57-86

www.usp.br/tradterm

http://www.revistas.usp.br/tradterm/index 
NECKEL, F. M. - A questão da metalinguagem em uma disciplina de introdução aos estudos da tradução: uma proposta de unidade didática

Flávio Dino, a former judge and member of the Communist Party of Brazil, glided to victory in the governor's race in October against the candidate allied with the Sarney family by campaigning on a platform of raising living standards.

Mr. Sarney was born in a town in the interior of Maranhão in 1930 as José Ribamar Ferreira de Araújo Costa. He took his father's foreign-sounding first name, Sarney, made it into a surname and began a political career with few parallels in Brazil.

A supporter of a coup in 1964 that ushered in a military dictatorship, he thrived during authoritarian rule before emerging in 1984 as the running mate of Tancredo Neves, the leader of Brazil's restoration of democracy. Elected president in 1985, Mr. Neves died of complications from intestinal surgery before taking office, opening the way for Mr. Sarney's rise to power.

Mr. Sarney, whose aides said he was unavailable for an interview, left office in 1990 with an approval rating of just 14 percent amidscathing criticism over management of the economy. At the time, Brazil grappled with an annual inflation rate of 1,765 percent.

Then Mr. Sarney reinvented himself as a senator representing Amapá, a territory in the Amazon made into a state in 1991, overseeing the growth of the family's media empire and the entrance of his children into politics. He rose to prominence again over the last decade as a president of the Senate, while battling claims of nepotism and corruption.

His daughter, Roseana, the departing governor of Maranhão, is celebrated in the pages of the family newspaper (a front-page photograph in November showed her strumming a guitar while visiting a school). But her last year in office was hit by a crisis over prison uprisings involving decapitations and reports that gangs were raping inmates' wives during conjugal visits.

Citing personal reasons, Ms. Sarney stepped down this month with only weeks left in her latest term, avoiding the ceremony of transferring the governor's sash to her successor on Jan. 1. Meanwhile, testimony in a hugebribery scandal involving the national oil company has linked her to the scheme. Ms. Sarney, who has denied the claims, also declined a request for an interview.

Some in Maranhão doubt that the Sarney family will now sit back and simply watch its opponents wield power. In fact, Ms. Sarney was knocked out of the governor's palace once before, after the election of an opposition governor in 2006.

But he was ousted in the face of criticism in Sarney-controlled news media over vote-buying accusations, enabling Ms. Sarney to step in and replace him.

Her father, the family patriarch, remains defiant even at the end of his long political career. Writing in his Sunday column about the "new Maranhão," Mr. Sarney said the state resembled "a body without a head" before he became governor in the 1960s.

"Today's generation has no notion of that struggle; the largest victory of all was changing the mentality of Maranhão," Mr. Sarney said. "It was so strong that it produced a president of the republic, and Maranhão emerged as one of the most important states in the country." 
NECKEL, F. M. - A questão da metalinguagem em uma disciplina de introdução aos estudos da tradução: uma proposta de unidade didática

FICHA 1: Trechos a serem traduzidos

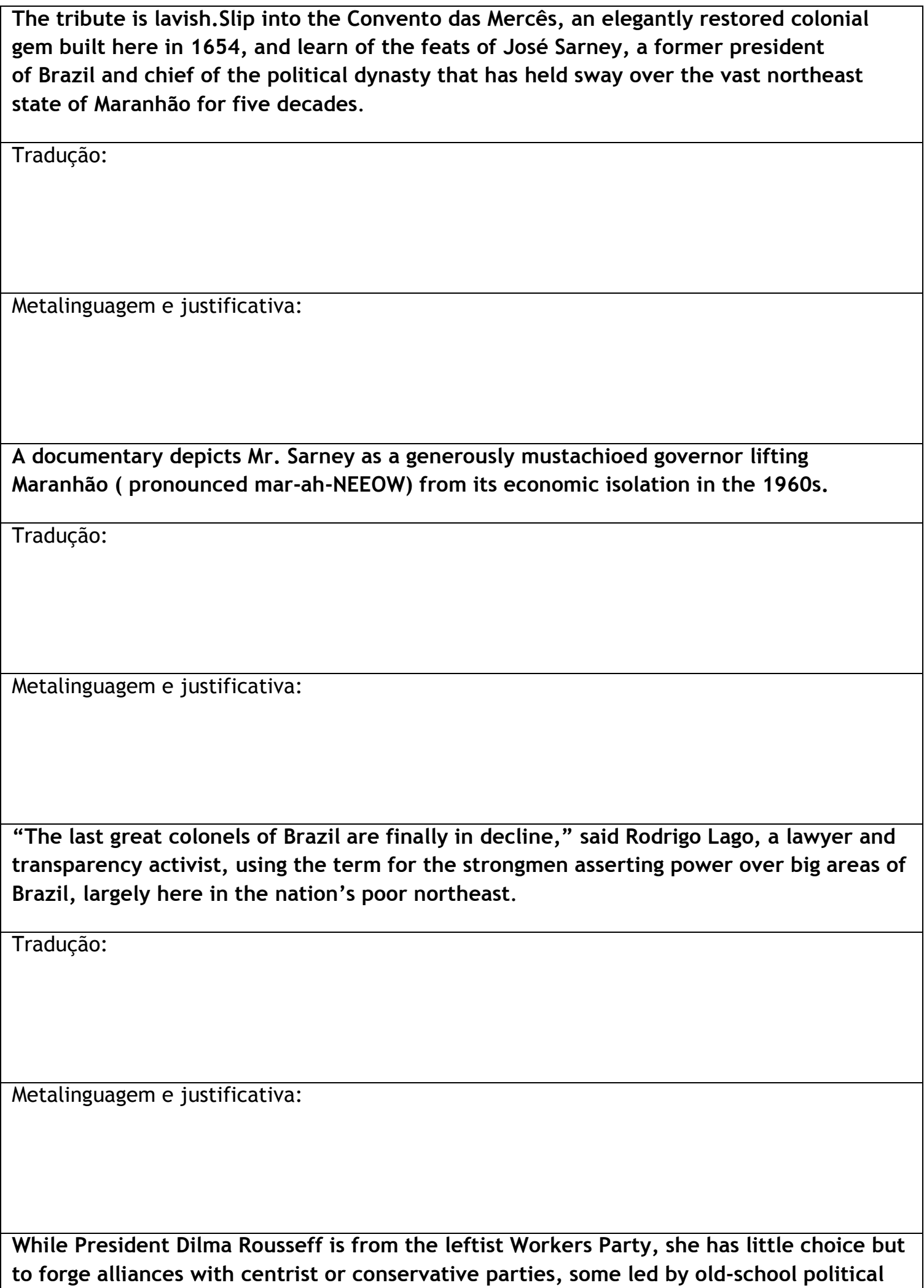


NECKEL, F. M. - A questão da metalinguagem em uma disciplina de introdução aos estudos da tradução: uma proposta de unidade didática

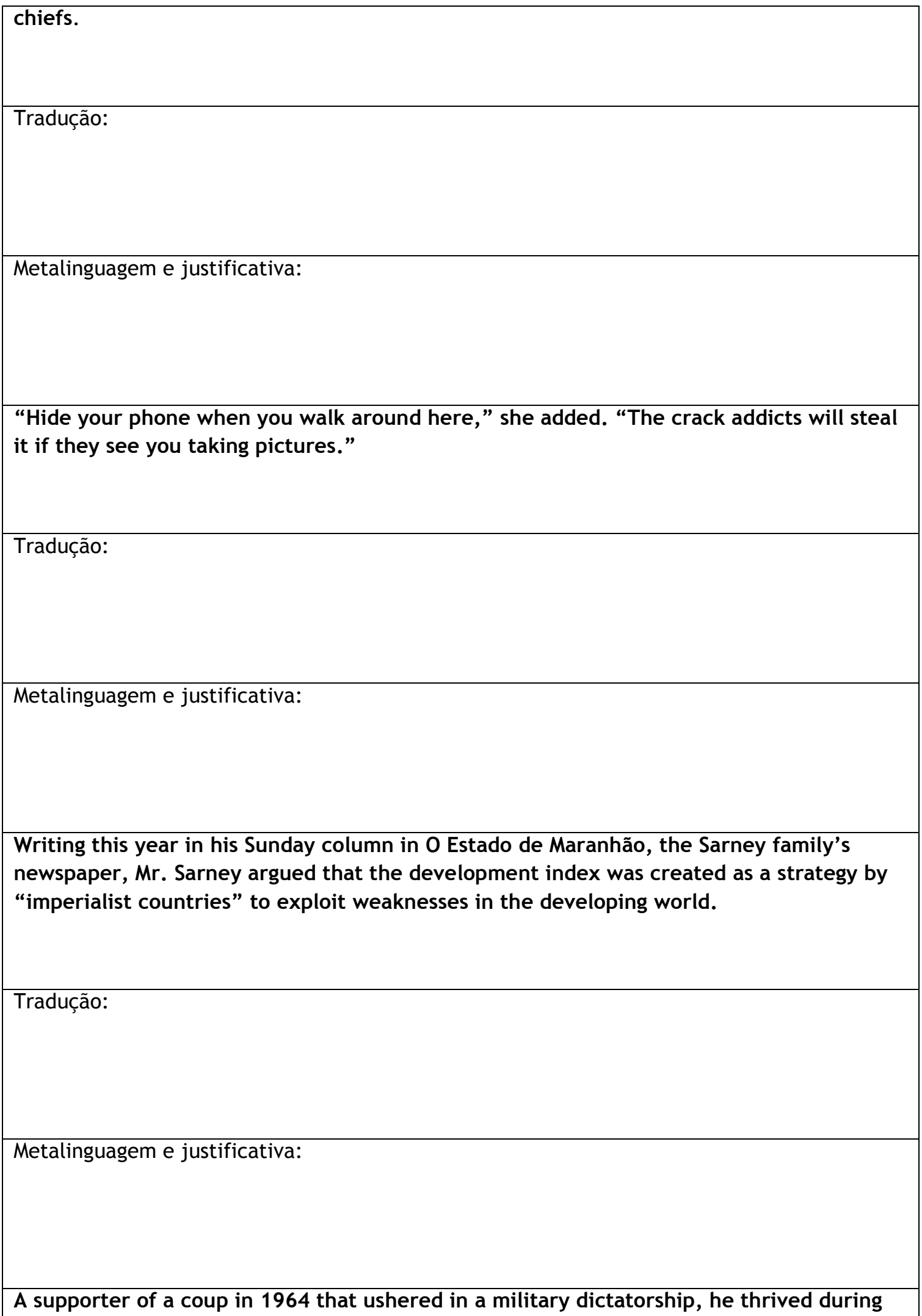

TradTerm, São Paulo, v. 26, Dezembro/2015, pp. 57-86

www.usp.br/tradterm

http://www.revistas.usp.br/tradterm/index 
NECKEL, F. M. - A questão da metalinguagem em uma disciplina de introdução aos estudos da tradução: uma proposta de unidade didática

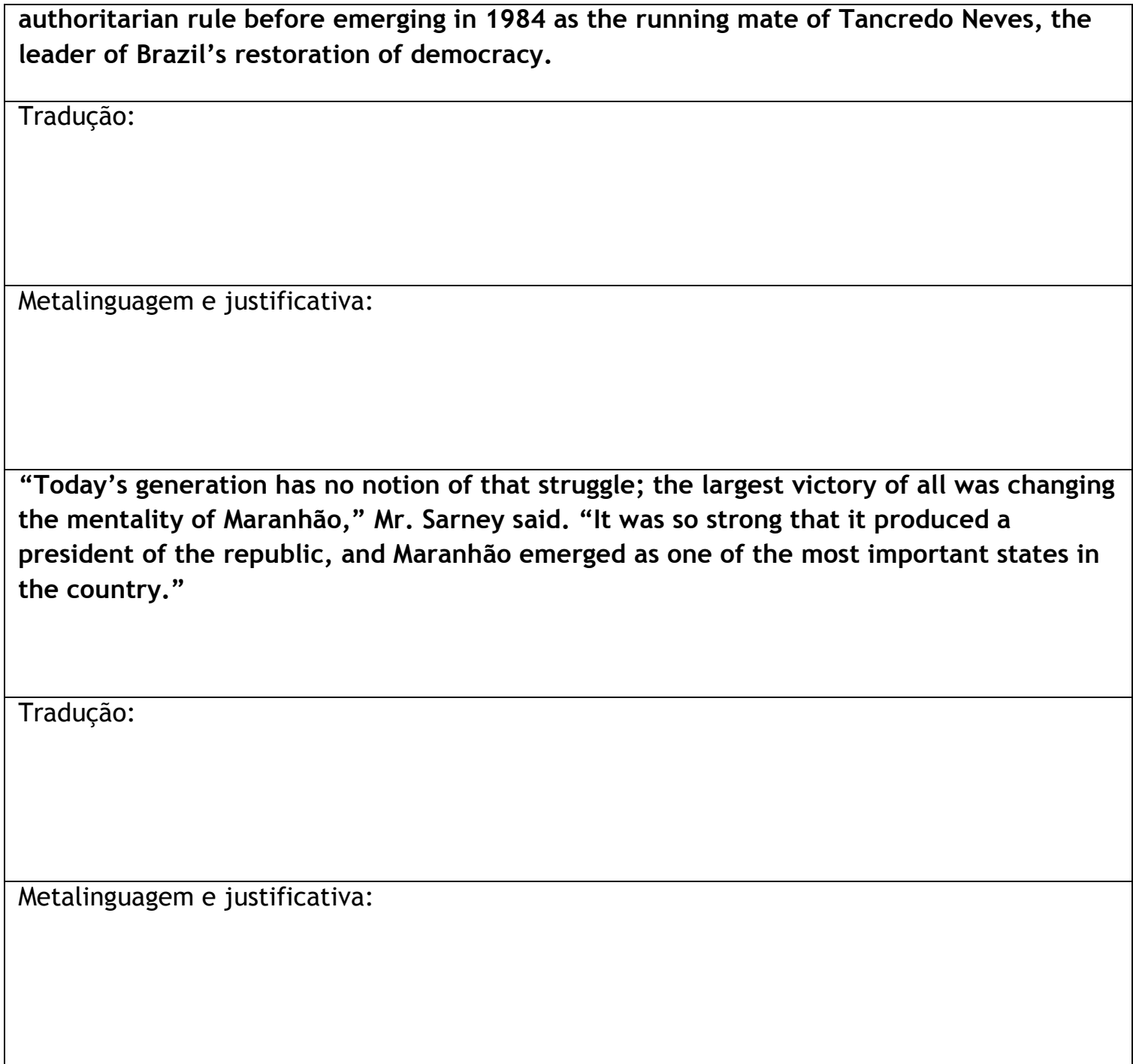


NECKEL, F. M. - A questão da metalinguagem em uma disciplina de introdução aos estudos da tradução: uma proposta de unidade didática

\section{Referencial bibliográfico:}

DeLISLE, J. L'Analyse du discours comme méthode de traduction. Editions de l'Université d'Ottawa, 1980.

d’Ottawa, 1993.

- La traduction raisonnée. Les Presses de l'Université

Barbosa, H. G. Procedimentos técnicos da tradução: uma nova proposta. Campinas, SP: Pontes, 2004.

HuRTado AlBiR, A. 1999. Enseñar a traducir. Metodología en la formación de traductores e intérpretes. Col. Investigación didáctica. Madrid: Edelsa.

RoBerTs, R. P. The terminology of translation. Meta, v. 30, n. 4, pp. 343-352, 1985.

\section{Material:}

http://www.nytimes.com/2014/12/26/world/decline-of-a-political-familyopens-the-way-for-a-shift-in-brazil.html?ref=americas 